\title{
Dataset dictionary
}

\begin{tabular}{|c|c|}
\hline Variable & Definition \\
\hline HHID & Household identifier \\
\hline intervention & $\begin{array}{l}\text { Monitored intervention (Categories 1-13) } \\
\text { 1= Folic Acid } \\
2=\text { Exclusive breastfeeding } \\
3=\text { Control visit throughout pregnancy } \\
4=\text { Powdered micronutrients } \\
5=\text { Ferrous sulphate } \\
6=\text { BCG } \\
7=\text { DPT } 10 \\
8=\text { Pentavalent } \\
9=\text { Polio } \\
\text { 10= OPV } 10 \\
11=\text { Rotavirus } \\
\text { 12= MMR (Measles, Mumps, Rubella) } \\
13=\text { Vitamin A }\end{array}$ \\
\hline treatment & $1=$ Phone calls, $2=$ Text messages \\
\hline reminders & $1=$ Household received SMS reminder, $0=$ Household did not receive SMS reminder \\
\hline validanswer & $1=$ Valid answer, $0=$ Invalid answer \\
\hline received & $\begin{array}{l}1=\text { Monitored individual received the intervention, } 0=\text { Monitored individual did not } \\
\text { receive intervention }\end{array}$ \\
\hline male & $1=$ Household head is male, $0=$ Household head is female \\
\hline age & Household head age \\
\hline nonsp_lang & $\begin{array}{l}\text { 1= Household head speaks non-Spanish language, } 0=\text { Household head speaks Spanish } \\
\text { language }\end{array}$ \\
\hline educ00 & $1=$ Household head has non-education, $0=$ Other \\
\hline educ01 & $1=$ Household head has elementary education, $0=$ Other \\
\hline educ02 & $1=$ Household head has secondary education, $0=$ Other \\
\hline size & Number of household members \\
\hline
\end{tabular}




\begin{tabular}{|l|l|}
\hline \multicolumn{1}{|c|}{ Variable } & \\
\hline subject & $\begin{array}{l}\text { Monitored individual (Categories 1-2) } \\
\text { 1= Pregnant women } \\
\text { 2= Child under 2 years old }\end{array}$ \\
\hline vaccine_int & 1= Vaccine intervention, 0= Other intervention \\
\hline distance & Distance to the health center (in minutes) \\
\hline mun & $\begin{array}{l}\text { Municipality (Categories } 1-2) \\
\text { 1= Municipality } 1\end{array}$ \\
2= Municipality 2 \\
\hline community & Community Identifier \\
\hline distance_o & 1= Distance to the health center imputed, $0=$ Other \\
\hline educ_o & 1= Household head education imputed, $0=$ Other \\
\hline
\end{tabular}

